\title{
Case-control study of occupational exposures and male breast cancer
}

\author{
P Cocco, L Figgs, M Dosemeci, R Hayes, M S Linet, A W Hsing
}

Institute of

Occupational

Medicine, University of Cagliari, Italy

P Cocco

St Louis University

School of Public

Health, St Louis, MO,

USA

L Figgs

Division of Cancer Epidemiology and Genetics, National

Cancer Institute,

Bethesda, MD, USA

$\mathrm{M}$ Dosemeci

$\mathrm{R}$ Hayes

M S Linet

A W Hsing

Correspondence to:

Dr Ann W Hsing, Division of

Cancer Epidemiology and

Genetics, National Cancer

Institute, 6130 Executive

Boulevard, EPN room 443

Bethesda, MD 20892, USA.

Telephone 001301496

1691; fax 001301402 0916;

email

HsingA@epndce.nci.nih.gov

Accepted 4 March 1998

\begin{abstract}
Objective-To investigate whether risk of male breast cancer is associated with workplace exposures.
\end{abstract}

Methods-A case-control study of 178 cases of male breast cancer and 1041 controls was carried out with data from the United States national mortality followback survey, which collected questionnaire information from proxy respondents of a $1 \%$ sample of all 1986 United States deaths among subjects aged 25-74 years. Occupational exposure to electromagnetic fields, high temperatures, polycyclic aromatic hydrocarbons (PAHs), herbicides, other pesticides, and organic solvents was assessed by applying job-exposure matrices, based on the 1980 United States census occupation and industry codes, to the longest job held by study subjects as reported by the informants. A socioeconomic status index was created by combining information on annual family income, education, assets, and occupation to assess the association of socioeconomic status with male breast cancer. Relative risks were derived from logistic regression modelling, which included age, socioeconomic status, marital status, and body mass index, as well as occupational exposures.

Results-Risk of male breast cancer increased significantly with increasing socioeconomic status index (test for trend: $\mathbf{p}<$ 0.01 ), but the risks associated with individual socioeconomic status variables were smaller and the trends were not significant. A significant increase in risk of male breast cancer was associated with employment in blast furnaces, steel works, and rolling mills (odds ratio (OR) $3.4 ; 95 \%$ confidence interval $(95 \%$ CI $) 1.1$ to 10.1 , based on six cases), and motor vehicle manufacturing (OR $3.1 ; 95 \%$ CI 1.2 to 8.2 , based on seven cases). However, exposures to electromagnetic fields, high temperature, PAHs, herbicides, other pesticides, and organic solvents were not associated with risk of male breast cancer.

Conclusions-The role of workplace exposures in increasing risk of breast cancer among men employed in motor vehicle manufacturing and in blast furnaces, steel works, and rolling mills deserves further investigation. The finding on socioeconomic status suggests that, as well as reproductive factors, other lifestyle factors such as diet that may be related to high socioeconomic status in men should be investigated further.

(Occup Environ Med 1998;55:599-604)

Keywords: male breast cancer; socioeconomic status; occupation

It is widely accepted that breast cancer is the same disease entity among women and men. ${ }^{1}$ All histological types reported among women also occur among men, ${ }^{2}$ and p53 gene mutations have been reported with the same frequency in the tumour tissue of male and female patients with breast cancer. ${ }^{3}$ Investigation of male breast cancer aetiology may provide unique clues for environmental and occupational risk factors that might be difficult to uncover in women, because of confounding or effect modification associated with parity, childbearing, breast feeding, age at menstruation, and other female characteristics.

Oestrogen receptor positive breast cancer has been reported to be more prevalent among men than among women, ${ }^{2}$ and the association of male breast cancer with risk factors, such as history of gynaecomastia, ${ }^{2-5}$ and Klinefelter's syndrome, ${ }^{16}$ suggests that hormonal imbalance - such as an excess of oestrogen-may play a part. Oestrogens in men are derived mainly from extragonadal tissues, and particularly adipose tissue, by enzymatic transformation of testosterone and androstenedione. Therefore, lifestyle and occupational factors affecting androgen production and metabolism may also be relevant in male breast cancer aetiology. Various conditions affecting the male hormonal balance have been reported in association with an increased risk of breast cancer in men..$^{4-68}$ Associations of female and male breast cancer with occupational exposure to electromagnetic fields (EMFs) have been reported previously. ${ }^{9-12}$ It has been hypothesised that EMFs might affect pineal gland activity leading to a reduced synthesis of melatonin, known to suppress the growth of oestrogen receptor positive tumours in laboratory experiments. ${ }^{12}$ Occupational exposure to high temperatures has also been associated with increased risk of breast cancer among men, ${ }^{14}{ }^{15}$ due to possibly testicular damage resulting from the increased temperature. Also, excess risk of male breast cancer has been found in association with occupational exposure to oestrogens in the cosmetic ${ }^{16}$ and pharmaceutical industries. ${ }^{17}$ 
In this report, we investigated the association of risk of male breast cancer with six occupational exposures and socioeconomic status, using data from the 1986 national mortality follow back survey.

\section{Methods}

The national mortality follow back survey has been described in detail elsewhere. ${ }^{18}$ Briefly, a $10 \%$ systematic sample of 1986 death certificates was provided by each United States state (excluding Oregon) to the National Center for Health Statistics. Questionnaires were sent to the proxy respondents of a sample of about $1 \%$ of 1986 United States deaths among subjects aged 25-74 years and of all 1985 deaths from several rare cancers, including cancer of the nasopharynx, nasal cavities, adrenal gland, liver in young women, small intestine, and male breast. The questionnaires obtained information on sociodemographic variables, longest held occupation and industry, height, weight, frequency of consumption of selected dietary items, use of cigarettes and alcohol, and medical history.

A total of 201 cases of death from male breast cancer were identified among decedents aged 25-74 years. After excluding 20 nonrespondents and three subjects who did not match the age and race inclusion criteria, a total of 178 cases remained available for study. A previous paper based on the same data set, focusing on lifestyle risk factors, comparing four selected controls to each index case, reported a positive association with body mass index (BMI) but no association with smoking or drinking. ${ }^{19}$ In our analysis of occupational exposures, because the numbers in each 3-digit occupation and industry code were small, we selected six controls for each index case to increase the statistical power of the study. The process of control selection was similar to that in our previous paper. $^{19}$ Controls were selected from all other causes of death and matched to index cases on the basis of 5-year age group, race (only white and African-American subjects), and region of death. A total of 1188 controls were selected for the analysis. Of these, 147 nonrespondents $(12 \%)$ were excluded, leaving 1041 controls for the final analysis.

To evaluate risks of male breast cancer relative to occupational exposures suggested by previous studies, ${ }^{9-17}$ job-exposure matrices were developed for EMFs, solvents, herbicides, other pesticides (mainly insecticides and fungicides), high temperatures in the workplace, and polycyclic aromatic hydrocarbons (PAHs), based on the 3-digit occupation and industry codes from the 1980 census of population. ${ }^{20}$ Job exposure matrices included an estimate of intensity level (none $=0$, low $=1$, medium $=2$, high=3) and probability (none $=0$, low $=1$, medium $=2$, high $=3$ ) of exposure for each risk factor for all 3-digit occupation and industry codes. Level of intensity of exposure was estimated based on information from the literature, ${ }^{2122}$ computerised exposure databases (Occupational Safety and Health Administration files, National Institute for Occupa-
Table 1 Selected characteristics among cases of male breast cancer and controls

\begin{tabular}{|c|c|c|c|c|}
\hline \multirow[b]{2}{*}{ Selected characteristics } & \multicolumn{2}{|c|}{ Cases } & \multicolumn{2}{|c|}{ Controls } \\
\hline & $n$ & $\%$ & $n$ & $\%$ \\
\hline Total & 178 & 100.0 & 1041 & 100.0 \\
\hline \multicolumn{5}{|l|}{ Age at death: } \\
\hline $25-34$ & 1 & 0.6 & 12 & 1.1 \\
\hline $35-44$ & 10 & 5.6 & 59 & 5.7 \\
\hline $45-54$ & 34 & 19.1 & 193 & 18.5 \\
\hline $55-64$ & 66 & 37.1 & 362 & 34.8 \\
\hline $65-74$ & 67 & 37.6 & 415 & 39.9 \\
\hline \multicolumn{5}{|l|}{ Race: } \\
\hline White & 161 & 90.4 & 941 & 90.4 \\
\hline African American & 17 & 9.6 & 100 & 9.6 \\
\hline \multicolumn{5}{|l|}{ Marital status: } \\
\hline Never married & 20 & 11.2 & 99 & 9.5 \\
\hline Divorced or separated & 20 & 11.2 & 180 & 17.3 \\
\hline Widowed & 17 & 9.6 & 80 & 7.7 \\
\hline Married & 118 & 66.3 & 662 & 63.6 \\
\hline Missing & 3 & 1.7 & 20 & 1.9 \\
\hline \multicolumn{5}{|l|}{ Type of respondent: } \\
\hline Spouse & 96 & 53.9 & 600 & 57.6 \\
\hline Parent & 28 & 15.7 & 153 & 14.7 \\
\hline Child & 7 & 3.9 & 51 & 4.9 \\
\hline Sibling & 24 & 11.1 & 107 & 10.3 \\
\hline Other & 23 & 14.3 & 130 & 12.5 \\
\hline
\end{tabular}

tional Safety and Health inspections database), unpublished industrial hygiene reports, and consensus between an experienced industrial hygienist (MD) and an occupational health physician (PC). Probability of exposure was estimated based on the proportion of exposed subjects within a given job title or industry, and the number of occupations or industries with the same 1980 3-digit census code. Also, occupational codes were characterised into two groups depending on whether occupation alone was enough to assess exposure (group A-for example, electrician for EMFs, roofer for PAHs, or painter for organic solvents), or whether the industry was indispensable (group B-for example, occupations such as labourer or driver). To have a uniform scale of probability and intensity scores in these two groups, among subjects with group A occupations, an intensity score and a probability score were calculated as the square of the intensity or the probability level associated with the respective occupation. Among subjects with group B occupations, intensity and probability scores resulted from multiplying the respective levels of occupation and industry. Probability and intensity scores were finally categorised into

Table 2 ORs for male breast cancer associated with socioeconomic status and related variables

\begin{tabular}{|c|c|c|c|c|}
\hline Socioeconomic variables & Cases & Controls & $O R$ & $95 \% C I$ \\
\hline \multicolumn{5}{|l|}{ Socioeconomic index: ${ }^{\star \star}$} \\
\hline Low & 72 & 534 & 1.0 & - \\
\hline Medium & 68 & 361 & 1.5 & 1.0 to 2.3 \\
\hline High & 36 & 143 & 2.3 & 1.4 to 3.8 \\
\hline \multicolumn{5}{|l|}{$\begin{array}{l}\text { Annual family income } \\
(\$) \text { : }\end{array}$} \\
\hline$\leqslant 4999$ & 38 & 242 & 1.0 & - \\
\hline $5000-49999$ & 54 & 351 & 0.9 & 0.6 to 1.5 \\
\hline$\geqslant 50000$ & 47 & 202 & 1.5 & 0.9 to 2.5 \\
\hline \multicolumn{5}{|l|}{ Assets (\$): } \\
\hline$\leqslant 4999$ & 39 & 279 & 1.0 & - \\
\hline 5000-49999 & 36 & 280 & 1.0 & 0.6 to 1.7 \\
\hline$\geqslant 50000$ & 69 & 279 & 2.0 & 1.2 to 3.2 \\
\hline \multicolumn{5}{|l|}{ Education: ${ }^{\star \star}$} \\
\hline$\leqslant 8 \mathrm{y}$ & 31 & 245 & 1.0 & - \\
\hline $\begin{array}{l}9 \mathrm{y}-\text { completed high } \\
\text { school }\end{array}$ & 87 & 520 & 1.3 & 0.8 to 2.2 \\
\hline$\geqslant 1$ y of college & 51 & 211 & 2.1 & 1.2 to 3.6 \\
\hline
\end{tabular}

$\star \star \mathrm{p}<0.01$ test for trend. 
Table 3 ORs for male breast cancer associated with occupations with at least three exposed cases

\begin{tabular}{llrlll}
\hline Code & Occupation & Cases & Controls & OR & 95\% CI \\
\hline 019 & Managers and administrators & 13 & 46 & 1.5 & 0.8 to 3.0 \\
055 & Electric and electronic engineers & 3 & 6 & 2.7 & 0.7 to 11.4 \\
174 & Social workers & 4 & 2 & 5.6 & 0.9 to 35.2 \\
243 & Supervisors and proprietors & 5 & 28 & 0.8 & 0.3 to 2.3 \\
& (sales occupations) & 4 & 16 & 1.3 & 0.8 to 2.3 \\
259 & Sales representatives & 3 & 4 & 6.1 & 1.3 to 28.6 \\
263 & Sales workers (motor vehicles and boats) & 3 & 46 & 0.4 & 0.1 to 1.2 \\
473 & Farmers & 4 & 22 & 1.2 & 0.4 to 3.5 \\
567 & Carpenters & 4 & 17 & 1.5 & 0.5 to 4.6 \\
633 & Supervisors (production occupations) & 3 & 2 & 8.2 & 1.3 to 50.4 \\
696 & Stationary engineers & 4 & 13 & 1.9 & 0.6 to 6.1 \\
777 & Miscellaneous machine operators & 8 & 50 & 1.1 & 0.5 to 2.4 \\
804 & Lorry drivers (heavy) & 3 & 6 & 4.8 & 1.1 to 20.1 \\
809 & Taxicab drivers & 5 & 31 & 0.9 & 0.3 to 2.7 \\
869 & Construction labourers & 9 & 35 & 1.8 & 0.8 to 3.8 \\
889 & Labourers (except construction) & & & & \\
\hline
\end{tabular}

four levels (none, low $=1$, medium $=2-4$, high $\geqslant 6$ ). Risk of male breast cancer was also evaluated for each specific occupation and industry with at least three cases.

To investigate the effect of occupational exposures independent of socioeconomic status, we created three socioeconomic status categories by combining information on family income, value of property at death, education, and occupation. Based on the tertile distribution of the single variables, low socioeconomic status was defined by an annual family income lower than $\$ 15000$, education lower than high school, and less than $\$ 100000$ in assets. High socioeconomic status was defined by an annual family income of $\$$ 25000 or higher, high school graduation or higher education, and $\$ 250000$ or more in assets. Intermediate values were included in the medium socioeconomic status category. When information was not available for family income, an estimate of socioeconomic status was constructed, based on three broad categories of occupation considered in combination with at least one of the other variables. A total of 13 combinations were identified and they were further combined into three socioeconomic status levels. Socioeconomic status was assigned a missing value only when all four variables were missing.

Odds ratios (ORs) were estimated by logistic regression and 95\% confidence intervals (95\% CIs) by the Wald method using the GMBO program in the Epicure software package. ${ }^{23}$ Variables in the logistic regression models were age (5-year age-groups), marital status (never married $v$ ever married),

Table 4 ORs for male breast cancer associated with industries with at least three exposed cases

\begin{tabular}{llrrll}
\hline Code & Industry & Cases & Controls & OR & 95\% CI \\
\hline 010 & Agricultural production (crops) & 3 & 55 & 0.3 & 0.1 to 1.1 \\
060 & Construction & 15 & 121 & 0.7 & 0.4 to 1.3 \\
231 & Saw mills, planing mills, and millwork & 3 & 5 & 4.0 & 0.9 to 17.4 \\
270 & Blast furnaces, steelworks, rolling and & & & & \\
& finishing mills & 6 & 11 & 3.4 & 1.1 to 10.1 \\
351 & Motor vehicles and motor vehicle equipment & 7 & 16 & 3.1 & 1.2 to 8.2 \\
392 & Not specified manufacturing industries & 4 & 18 & 1.4 & 0.5 to 4.2 \\
400 & Railways & 3 & 17 & 1.0 & 0.3 to 3.7 \\
410 & Heavy goods vehicle service & 6 & 43 & 0.9 & 0.4 to 2.2 \\
412 & United States postal service & 5 & 14 & 1.9 & 0.6 to 5.5 \\
550 & Groceries and related products & 4 & 5 & 4.0 & 0.9 to 17.7 \\
641 & Eating and drinking places & 7 & 18 & 2.2 & 0.9 to 5.4 \\
831 & Hospitals & 4 & 12 & 1.6 & 0.4 to 5.8 \\
842 & Elementary and secondary schools & 3 & 15 & 0.8 & 0.2 to 2.8 \\
910 & Justice, public order, and safety & 3 & 15 & 1.1 & 0.3 to 3.9 \\
\hline
\end{tabular}

socioeconomic status (three categories), and body mass index (BMI) tertiles $\left(\mathrm{kg} / \mathrm{m}^{2}\right.$ (23, $23.1-25.9, \geqslant 26)$ ). Additional analyses were performed adding variables for alcohol use (in quartiles of drinks a week) and cigarette smoking (non-smokers, ex-smokers, current smokers). The significance of the trend for increasing level of the categorised variables was tested by dividing each regression coefficient by its standard error to generate a $\mathrm{Z}$ statistic. Under the null hypothesis, this test behaves as a normal standard deviate. ${ }^{24}$ Two tailed $\mathrm{p}$ values were considered throughout this article.

\section{Results}

Selected characteristics of the study populations are reported in table 1 . Less than $10 \%$ of cases and controls were African-Americans. The proportion of never-married subjects was greater among cases, who also had more years of education and higher annual family income than controls. Respondents other than family members were more often represented among cases than among controls.

As shown in table 2, risk of male breast cancer is associated positively with socioeconomic status index, with a significant positive trend $(p<0.01)$. Risk also increased with increasing level of a few individual socioeconomic status variables, including annual family income, assets, and education, but the magnitude was generally smaller, and only the trend for education was significant.

As shown in table 3, a significant increase in risk was found for sales workers (motor vehicles and boats), stationary engineers, and taxicab drivers, all based on three cases. Industries associated with a significant increase in risk were: blast furnaces, steelworks, rolling and finishing mills (six cases), and manufacturing of motor vehicles and motor vehicle equipment (seven cases, table 4). Among occupations and industries of initial interest, a non-significant excess risk was found among electric and electronic engineers, whereas no study subjects had their longest employment in the cosmetic manufacturing industry, and only one control and no cases had been employed in drug manufacturing.

Risks associated with probability and intensity of exposure to six occupational hazards are shown in table 5 . We did not find significant associations with male breast cancer or a consistent increase in risk of male breast cancer by either probability or intensity of exposure to any of the six risk factors considered in this study. Exploring risk by cross classification of probability and intensity of exposure did not show any increasing trend with exposure to EMFs, PAHs, or organic solvents. The number of exposed people was too small for a cross classification of probability and intensity of exposure to high temperatures, herbicides, or other pesticides. Occupations and industries contributing to exposure to PAHs, solvents, EMFs, and high temperatures were diverse, but only a few had enough cases for estimating risk. Twelve study subjects were classified with high probability and high intensity of exposure to 
Table 5 ORs for male breast cancer associated with potential occupational exposures assessed by job exposure matrices

\begin{tabular}{|c|c|c|c|c|}
\hline Exposure & Cases & Controls & $O R$ & $95 \% C I$ \\
\hline \multicolumn{5}{|l|}{ Electromagnetic fields: } \\
\hline Unexposed & 122 & 708 & 1.0 & - \\
\hline \multicolumn{5}{|c|}{ Probability of exposure: } \\
\hline Low & 30 & 177 & 1.0 & 0.6 to 1.6 \\
\hline Medium & 7 & 40 & 1.2 & 0.5 to 3.1 \\
\hline High & 19 & 116 & 1.1 & 0.6 to 1.9 \\
\hline \multicolumn{5}{|c|}{ Intensity of exposure: } \\
\hline Low & 31 & 167 & 1.0 & 0.6 to 1.7 \\
\hline Medium & 16 & 111 & 1.1 & 0.6 to 2.0 \\
\hline High & 9 & 55 & 1.0 & 0.5 to 2.1 \\
\hline \multicolumn{5}{|l|}{ High temperatures: } \\
\hline Unexposed & 164 & 940 & 1.0 & - \\
\hline \multicolumn{5}{|c|}{ Probability of exposure: } \\
\hline Low & 7 & 32 & 1.6 & 0.6 to 3.8 \\
\hline Medium & 2 & 20 & 0.8 & 0.2 to 3.6 \\
\hline High & 5 & 49 & 0.5 & 0.2 to 1.5 \\
\hline \multicolumn{5}{|c|}{ Intensity of exposure: } \\
\hline Low & 2 & 16 & 0.8 & 0.2 to 3.5 \\
\hline Medium & 6 & 40 & 0.8 & 0.3 to 2.3 \\
\hline High & 6 & 45 & 0.9 & 0.4 to 2.3 \\
\hline \multicolumn{5}{|l|}{ Herbicides: } \\
\hline Unexposed & 170 & 961 & 1.0 & - \\
\hline \multicolumn{5}{|c|}{ Probability of exposure: } \\
\hline Low + medium & 3 & 24 & 0.9 & 0.2 to 3.1 \\
\hline High & 5 & 56 & 0.5 & 0.2 to 1.3 \\
\hline \multicolumn{5}{|l|}{ Intensity of exposure } \\
\hline Low + medium & 1 & 3 & 1.8 & 0.2 to 18.8 \\
\hline High & 7 & 77 & 0.6 & 0.2 to 1.3 \\
\hline \multicolumn{5}{|l|}{ Other pesticides: } \\
\hline Unexposed & 162 & 900 & 1.0 & - \\
\hline \multicolumn{5}{|c|}{ Probability of exposure: } \\
\hline Low & 8 & 66 & 0.7 & 0.3 to 1.6 \\
\hline Medium & 2 & 19 & 0.7 & 0.2 to 3.4 \\
\hline High & 6 & 56 & 0.6 & 0.2 to 1.5 \\
\hline \multicolumn{5}{|c|}{ Intensity of exposure: } \\
\hline Low & 2 & 25 & 0.5 & 0.1 to 2.3 \\
\hline Medium & 7 & 43 & 1.0 & 0.4 to 2.3 \\
\hline High & 7 & 73 & 0.6 & 0.2 to 1.3 \\
\hline \multicolumn{5}{|c|}{ Polycyclic aromatic hydrocarbons: } \\
\hline Unexposed & 135 & 715 & 1.0 & - \\
\hline \multicolumn{5}{|c|}{ Probability of exposure: } \\
\hline Low & 13 & 62 & 1.3 & 0.7 to 2.6 \\
\hline Medium & 7 & 68 & 0.6 & 0.3 to 1.5 \\
\hline High & 23 & 196 & 0.7 & 0.4 to 1.2 \\
\hline \multicolumn{5}{|c|}{ Intensity of exposure: } \\
\hline Low & 25 & 218 & 0.7 & 0.5 to 1.2 \\
\hline Medium & 12 & 71 & 1.0 & 0.5 to 2.1 \\
\hline High & 6 & 37 & 1.0 & 0.4 to 2.5 \\
\hline \multicolumn{5}{|l|}{ Organic solvents: } \\
\hline Unexposed & 136 & 745 & 1.0 & - \\
\hline \multicolumn{5}{|c|}{ Probability of exposure: } \\
\hline Low & 26 & 188 & 0.8 & 0.5 to 1.3 \\
\hline Medium & 15 & 95 & 0.9 & 0.5 to 1.6 \\
\hline High & 1 & 13 & 0.5 & 0.1 to 4.3 \\
\hline Intensity of exposu & & & & \\
\hline Low & 18 & 127 & 0.8 & 0.4 to 1.4 \\
\hline Medium & 20 & 134 & 0.8 & 0.5 to 1.5 \\
\hline High & 4 & 35 & 0.7 & 0.2 to 2.1 \\
\hline
\end{tabular}

PAHs. Their occupations were: furnace operators in blast furnaces (one case and one control) and in the primary aluminum industry (zero cases and one control), firefighters (zero cases and seven controls), and roofers (zero cases and two controls). Only four subjects had high probability and high intensity of exposure to solvents, and they were two roofers (the same two controls also considered to be exposed to PAHs) and two hand painters in unspecified industries. Seven furnace operators (one case and six controls) in various industries, seven firefighters (the same controls also considered to be exposed to PAHs), and one subject with a hand moulding and casting job in a pottery had high probability and high intensity exposure to high temperatures. Fifty nine subjects had high probability and high intensity exposure to EMFs, and they had 10 different occupations: electrician (zero cases and 17 controls), welder (zero cases and 19 controls), and electric and electronic engineer (three cases and six controls) were the most prevalent. By contrast, farmers were the leading occupation for exposure to herbicides and to other pesticides.

\section{Discussion}

In this case-control study of male breast cancer, risk increased significantly with increasing level of socioeconomic status, as previously reported among women. ${ }^{25}$ Risk was significantly increased for medium socioeconomic status and further increased, up to 2.3-fold, for high socioeconomic status. Increases in risk were found also with individual economic indicators, but the magnitude was smaller and only education showed a significant trend. Also, as socioeconomic status categories were based on the combination of various indicators, occupational factors are not likely to be the underlying factor explaining the association. Excess risk of breast cancer among women in the higher social class is thought to be possibly related to differences in diet and in reproductive factors, such as parity, age at first birth, and age at menarche. ${ }^{25}$ Our finding of an increase in risk of male breast cancer with socioeconomic status index suggests that, as well as reproductive factors, other factors that are related to high socioeconomic status, such as diet or other lifestyle habits, may be important in breast cancer aetiology and deserve further investigation.

Previous reports of an excess risk of male breast cancer among workers in blast furnaces, steel works, and rolling and finishing mills ${ }^{15}$ were interpreted as possibly related to workplace exposure to high temperature, because of possible testicular damage. ${ }^{14}{ }^{1526}$ However, these previous positive findings were limited by small numbers and did not use a systematic approach for exposure assessment. We also found a significant excess risk associated with working in blast furnaces, steel works, and rolling and finishing mills, whereas none of the other occupations and industries considered to involve exposure to high temperatures in a previous paper ${ }^{14}$ was represented by at least three cases in the present study. When we applied a job-exposure matrix for workplace exposure to high temperatures to the longest occupation and industry of study subjects, we did not find an excess risk for male breast cancer associated with either probability or intensity of exposure to high temperatures. The six cases employed in the industries classified as blast furnaces, steelworks, and rolling and finishing mills had various occupations: one was an accounting clerk (no controls), another worked as furnace operator (one control), the third was a machinist (no controls), the fourth was a machine operator (three controls), the fifth was a welder (one control), and the sixth had an unspecified longest occupation in the questionnaire and he was reported as a heat treating equipment operator on the death certificate. Besides increased temperatures, these workers may have experienced a large variety of exposures, including dust, PAHs, nitrogen oxides, nitrosamines, and metal fumes. We only tested 
PAHs. Although any conclusion seems premature based on the present findings, the role of workplace exposures in blast furnaces, steel works, and rolling and finishing mills deserves further investigation.

An association between occupational exposure to EMFs and risk of breast cancer has been reported. ${ }^{9-12}$ In experimental animals, EMFs can influence circadian rhythms, which are accompanied by undulatory patterns of melatonin secretion, which suppresses the growth of oestrogen receptor positive tumours in laboratory experiments. ${ }^{10-13}$ A speculative link between exposure to EMFs and risk of breast cancer was therefore established as due to a reduced synthesis of melatonin. ${ }^{121327}$ However, we found no association with either probability or intensity of occupational exposure to EMFs. There has been considerable discussion about which method of assessing exposure to EMFs is most suitable for epidemiological use. ${ }^{28}$ Our job exposure matrix was not detailed enough to discriminate between various types of EMFs. Therefore, the role of occupational exposure to EMFs in the aetiology of breast cancer cannot be ruled out based on the present findings.

Exposure to organochlorine pesticides with oestrogenic properties has been linked to risk of breast cancer. ${ }^{29}$ Our results were negative for an association with occupational exposure to herbicides and other pesticides. However, these are broad categories of agricultural chemicals, and in the past decades the proportion of organochlorines among agricultural pesticides has been steadily decreasing, which might combine with the broad definition of pesticides in our job exposure matrix to obscure any positive finding in association with oestrogen-like organochlorine pesticides.

We considered exposure to PAHs because of reports of increased PAH adducts in breast cancer tissues, ${ }^{30}$ and because exposure to undefined hydrocarbons was considered as a risk factor for male breast cancer in a previous case-control study, together with solvents, pesticides, and herbicides. ${ }^{26}$ We found no association of risk of male breast cancer with occupational exposure to either PAHs or organic solvents.

Workplace environments typically involve exposure to a complex mixture of physical and chemical agents, any of which may be responsible for an observed association. Compared with occupation and industry titles alone, jobexposure matrices in epidemiological analyses offer the advantages of a clearer definition of the risk factor and of a greater statistical power resulting from assembling subjects with the same exposure in various occupations and industries. When set on the whole list of occupations and industries, instead of being based on the occupation and industry titles of the study subjects, job exposure matrices offer the additional advantage of a systematic approach to retrospective exposure assessment, although findings should be interpreted with caution. However, uncertainty and crudeness in exposure assessment are major obstacles in the interpretation of negative results in job exposure matrices. Indeed, non-differential expo- sure misclassification in a $2 \times 2$ table is known to bias a risk estimate toward the null condition, when a true association exists between exposure and disease. ${ }^{31}$ Detail in occupation and industry codes significantly affects precision in exposure assessment with job exposure matrices. ${ }^{32}$ In the national mortality follow back survey data, information on occupation and industry was obtained from the death certificates, and the longest occupation and industry from the questionnaires were coded with the three-digit 1980 census code, which may not be specific enough in identifying some of the exposures considered in the present study. Also, different opinions on exposure assessment were only discussed by the two coauthors who created the job exposure matrices and not by a panel of industrial hygienists. A larger discussion might have contributed to increasing the precision in exposure assessment and in preventing false negative results, if any occurred in this study.

Although this is the second largest study on male breast cancer to date, the statistical power to detect associations with specific occupations, industries, or occupational exposures was limited. Also, information was provided by proxy interviews and no complete work histories were available for the study subjects. This adds further exposure misclassification, thus increasing the potential for obscuring putative positive associations.

Smoking and drinking are linked to several occupations, and previous studies have shown that deceased controls are likely to be overrepresented with causes of death related to smoking and drinking. To minimise the confounding by smoking and drinking, we excluded controls with causes of death related to smoking or drinking and adjusted for smoking and drinking directly in the models. Both approaches, however, did not materially change the results.

In summary, as with female breast cancer aetiology, we found an increased risk of male breast cancer associated with higher socioeconomic status, suggesting the need to investigate further the role of other nonreproductive lifestyle factors that are related to socioeconomic status. The risk associated with work in blast furnaces, steel mills, and rolling and finishing mills, and with manufacturing of motor vehicles and motor vehicle equipment, needs to be confirmed by future studies.

Dr Pierluigi Cocco and Dr Larry Figgs contributed to this work while at the Division of Cancer Epidemiology and Genetics, National Cancer Institute, NIH, Bethesda, MD. The work of National Cancer Institute, NIH, Bethesda, MD. The work of $\mathrm{PC}$ at the National Cancer Institute was supported with funding from the International Union Against Cancer (Geneva, sels, Belgium).

1 Thomas DB. Breast cancer in men. Epidemiol Rev 1993;15:220-31.

2 Stalsberg H, Thomas DB, Rosenblatt KA, et al. Histologic types and hormone receptors in breast cancer in men: a population-based study in 282 United States men. Cancer Causes Control 1993;4:143-51.

3 Anelli A, Anelli TMF, Youngson B, et al. Mutations of the p53 gene in male breast cancer. Cancer 1995;75:2233-8.

4 Schottenfeld D, Lilienfeld AM, Diamond H. Some observations on the epidemiology of breast cancer among males. Am 7 Public Health 1963;53:890-7.

5 Olsson H, Ranstam J. Head trauma and exposure to prolactin-elevating drugs as risk factors for male breast cancer. $\mathcal{F}$ Natl Cancer Inst 1988;80:679-83. 
6 Meyskens FL, Tormey DC, Neifeld JP. Male breast cancer: a review. Cancer Treat Rev 1976;3:83-93.

7 Griffin JE, Wilson JD. Disorders of the testes and male reproductive tract. In: Wilson JD, Foster DW, eds. Textbook of endocrinology. Philapdelphia, PA: WB Saunders, 1985: 259-311.

8 Thomas DB, Jimenez M, McTiernan A, et al. Breast cancer in men: risk factors with hormonal implications. Am $\mathcal{F}$ Epidemiol 1992;135:734-48.

9 Tynes T, Andersen A. Electromagnetic fields and male breast cancer [letter]. Lancet 1990;336:1596.

10 Matanoski GM, Breysse PN, Elliott EA. Electromagnetic fields and male breast cancer [letter]. Lancet 1991;337:737.

11 Demers PA, Thomas DB, Rosenblatt KA, et al. OccupaDemers PA, Thomas DB, Rosenblatt KA, et al. Occupa-
tional exposure to electromagnetic fields and breast cancer in men. Am ₹ Epidemiol 1991;134:340-7.

12 Loomis DP, Savitz DA, Ananth CV. Breast cancer mortality among female electrical workers in the United States. $\mathcal{F}$ Natl Cancer Inst 1994;86:921-5.

13 Stevens R. Electric power use and breast cancer: a hypothesis. Am f Epidemiol 1987;125:556-61

14 Rosenbaum PF, Vena JE, Zielezny MA, et al. Occupational exposures associated with male breast cancer. Am f Epidemiol 1994;139:30-6.

15 Mabuchi K, Bross DS, Kessler II. Risk factors for male breast cancer. $\mathcal{F}$ Natl Cancer Inst 1985;74:371-5.

16 McLaughlin JK, Malker HSR, Blot WJ, et al Occupational risks for male breast cancer in Sweden. Br F Ind Med 1988; 45:275-6.

17 Hansen J, Olsen JH, Larsen AI. Cancer morbidity among employees in a Danish pharmaceutical plant. Int $\mathcal{f}$ 994:23:891-8.

18 Seeman I, Poe GS, Mc Laughlin JK. Design of the 1986 national mortality followback survey: considerations on collecting data on decedents. Public Health Rep 1989;104: 183-8

19 Hsing AW, Mc Laughlin JK, Co Chien HT, et al. Risk factors for male breast cancer. Cancer Causes Control 1998;9. 269-75.
20 Bureau of the Census. Alphabetical index of industries and occupations. Washington, DC: US Department of Commerce, 1982. (PHC80-R3.)

21 Zenz C. Occupational medicine. Principles and practical applications, 2nd ed. Chicago, IL: Yearbook Medical Publishers, 1988.

22 Parmeggiani L, ed. Encyclopedia of occupational health and safety, 3rd ed. Geneva, Switzerland: International Labour safety, 3rd ed.

23 Preston DL, Lubin JH, Pierce DA. Epicure. Seattle, WA: Hirosoft, 1990.

24 Breslow NE, Day NE. Statistical methods in cancer research Vol I. The analysis of case-control studies. Lyon: International Agency for Research on Cancer, 1980 (IARC Sci Publ No 32.)

25 Kelsey JL, Horn-Ross PL. Breast cancer: magnitude of the problem and descriptive epidemiology. Epidemiol Rev 1993;15:7-16.

26 Lenfant-Pejovic M-H, Mlika-Cabanne N, Bouchardy C, et al. Risk factors for male breast cancer: a Franco-Swiss case-control study. Int $\mathcal{F}$ Cancer 1990;45:661-5.

27 Heat CW. Electromagnetic field exposure and cancer: review of epidemiologic evidence. CA Cancer f Clin 1996; 65:29-44.

28 Poole C. Evolution of epidemiologic evidence on magnetic fields and childhood cancers. Am F Epidemiol 1996;143: 129-32.

29 Wolff MS, Toniolo PG, Lee EW, et al. Blood levels of organochlorine residues and risk of breast cancer. $\mathcal{F}$ Natl Cancer Inst 1993;85:648-52.

30 Perera FP, Estabrook A, Hewer A, et al. Carcinogen-DNA adducts in human breast tissue. Cancer Epidemiol Biomarkers Prev 1995;4:233-8.

31 Rothman KJ. Modern epidemiology. Boston, MA: Little, Brown, 1986

32 Dosemeci M, Cocco PL, Gomez M, et al. Effects of three features of a job-exposure matrix on risk estimates. Epidemiology 1994;5:124-7. 